\title{
Simultaneous Determination of Anthraquinones, Their 8- $\beta$-D-Glucosides, and Sennosides of Rhei Rhizoma by Capillary Electrophoresis
}

\author{
Junko Koyama, * Izumi Morita, Hirotaka Fujiyoshi, and Norihiro Kobayashi \\ Kobe Pharmaceutical University; Higashinada-ku, Kobe 658-8558, Japan. \\ Received November 4, 2004; accepted January 29, 2005
}

The simultaneous separation and determination of major anthraquinones (emodin, chrysophanol, rhein and their glucosides, aloe-emodin, sennoside A, and sennoside B) of Rhei Rhizoma were achieved by cyclodextrin modified capillary zone electrophoresis. The running electrolyte used in this method was 0.005 м $\alpha$-cyclodextrin in $0.03 \mathrm{~m}$ borate buffer ( $\mathrm{pH} 10.0$ ) containing $20 \%$ acetonitrile, with an applied voltage of $20 \mathrm{kV}$. coside

Key words cyclodextrin modified capillary zone electrophoresis; emodin; chrysophanol; rhein; sennoside; anthraquinone glu-

In a continuation of our work on quinones that occur widely in the plant kingdom and that may have biological activities, we have developed a simple cyclodextrin modified capillary zone electrophoresis (CD-CZE) to separate and determine emodin, chrysophanol, aloe-emodin, rhein, emodin8 - $\beta$-D-glucoside, chrysophanol-8- $\beta$-D-glucoside, rhein- 8 - $\beta$-Dglucoside, sennoside A, and sennoside B of Rhei Rhizoma. Rhei Rhizoma is an old- and well-known herbal medicine known for its purgative effect due to anthracene derivatives, especially their glycosides. The analysis of these compounds and anthraquinones in pharmaceutical preparations or in complex matrices such as crude plant extracts is, therefore, of special interest. ${ }^{1,2}$ Some naturally-occurring anthraquinones have already been examined by thin layer chromatography, ${ }^{3)}$ HPLC methods, ${ }^{4-8)}$ and capillary electrophoresis (CE),${ }^{9-14)}$ however, only a single component or limited components have been determined in the majority of them. A few simultaneous analyses of different types of components have been conducted. ${ }^{6,8,14)}$ Studies related to simultaneous determination by $\mathrm{CE}$ are especially rare. Rhei Rhizoma contains a wide variety of components, including monomeric anthraquinones, their glycosides, and dimeric anthrone glycosides, and thus simultaneous determination of these different groups of components showing large differences in polarity is desirable for the quality control of the herb. For this purpose, we have developed a simple and rapid CD-CZE method (except for rhein) using $0.005 \mathrm{~m} \alpha$-CD in $0.03 \mathrm{~m}$ borate buffer ( $\mathrm{pH} 10.0$ ) containing $20 \%$ acetonitrile.

\section{Experimental}

Reagents and Materials Sodium tetraborate, sodium dodecyl sulphate (SDS), sodium hydroxide, hydroxypropyl- $\beta$-CD (HP- $\beta$-CD), $\gamma$-CD, and HP$\gamma$-CD were purchased from Wako Pure Chemicals (Osaka, Japan), $\alpha$-CD, $\beta$ $\mathrm{CD}$, and sennoside A (8) from Nacalai Tesque (Kyoto, Japan), sennoside B (9) from Funakoshi (Tokyo, Japan), and boric acid from Fluka (Buchs, Switzerland). Acetonitrile, methanol, and water were of HPLC grade. Emodin (1) and chrysophanol (2) were isolated from the root bark of Cassia siamea ${ }^{15)}$ Emodin-8- $\beta$-D-glucoside (5) was isolated from the root of Polygonum cuspidatum SIEB. et Zucc. ${ }^{16,17)}$ and chrysophanol-8- $\beta$-D-glucoside (6) from Cascara Sagrada (the root of Rhamnus purshiana DC.). ${ }^{18,19)}$ Aloeemodin (3), rhein (4), and rhein-8- $\beta$-D-glucoside (7) were isolated from Rhei Rhizoma $^{20)}$ (Fig. 1). Rhei Rhizoma (Rheum palmatum L., Rheum tanguticum MaXiм.) was purchased from The Iguchi Pharmacy (Kobe, Japan).

Procedure for CE The CE analyses were carried out using a Beckman MDQ and P/ACE System 5000 apparatus (Fullerton, CA, U.S.A.) equipped with a UV detector set at $254 \mathrm{~nm}$, a diode array detector, and a Beckman untreated fused-silica capillary $(570 \mathrm{~mm} \times 75 \mu \mathrm{m}$ i.d.; $500 \mathrm{~mm}$ effective length). The analytical conditions were as follows: sampling time, $5 \mathrm{~s}$ (hydrodynamic mode; 0.5 p.s.i.); applied constant voltage, $20 \mathrm{kV}$; column temperature, $20{ }^{\circ} \mathrm{C}$. The CD-CZE electrolyte was a buffer solution prepared by mixing $0.03 \mathrm{~m}$ sodium tetraborate solution with the appropriate volumes of $10 \%$ sodium hydroxide ( $\mathrm{pH} 10.0$ ) followed by the addition of $0.005 \mathrm{~m} \alpha$-CD and $20 \%$ acetonitrile. Standard solutions were prepared by dissolving each compound in the electrolyte at a concentration of $c a .10 \mathrm{ppm}$. Among the peaks of the herbal extract, compounds $\mathbf{1}-\mathbf{9}$ were identified by spiking with standards and comparing with a UV Similarity Index (the value to compare UV spectra of an unknown compound against spectra of a known sample).

Sample Preparation of Extracts The powdered Rhei Rhizoma (10 g) was exhaustively extracted in a Soxhlet apparatus with methanol $(100 \mathrm{ml})$ for $10 \mathrm{~h}$. After concentration, the residue was diluted with methanol to $100 \mathrm{ml}$. This solution was passed through a $0.45 \mu \mathrm{m}$ filter. After centrifugation, $1 \mathrm{ml}$ of the methanol solution was diluted to $10 \mathrm{ml}$ with borate buffer ( $\mathrm{pH} 10.0$ ), yielding the sample for $\mathrm{CE}$ analysis.

\section{Results and Discussion}

We have studied the application of CE to the separation and the determination of anthraquinones, and found that due to the phenolic (and hence weak acidic) or neutral nature of the anthraquinones, the weak alkaline condition of the borate buffer ( $\mathrm{pH}$ 10.0) as an eluent could provide good resolution. Since all compounds $(\mathbf{1}-\mathbf{9})$ possess phenolic or carboxylic groups, CE using a buffer solution of borate with different $\mathrm{pH}$ values as the carrier was employed in our preliminary tri-
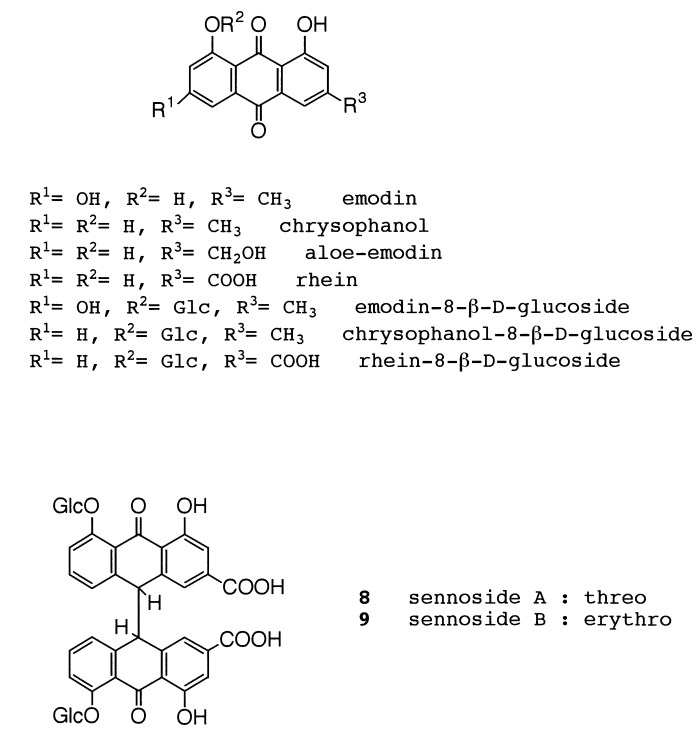

sennoside A : threo

sennoside B : erythro 


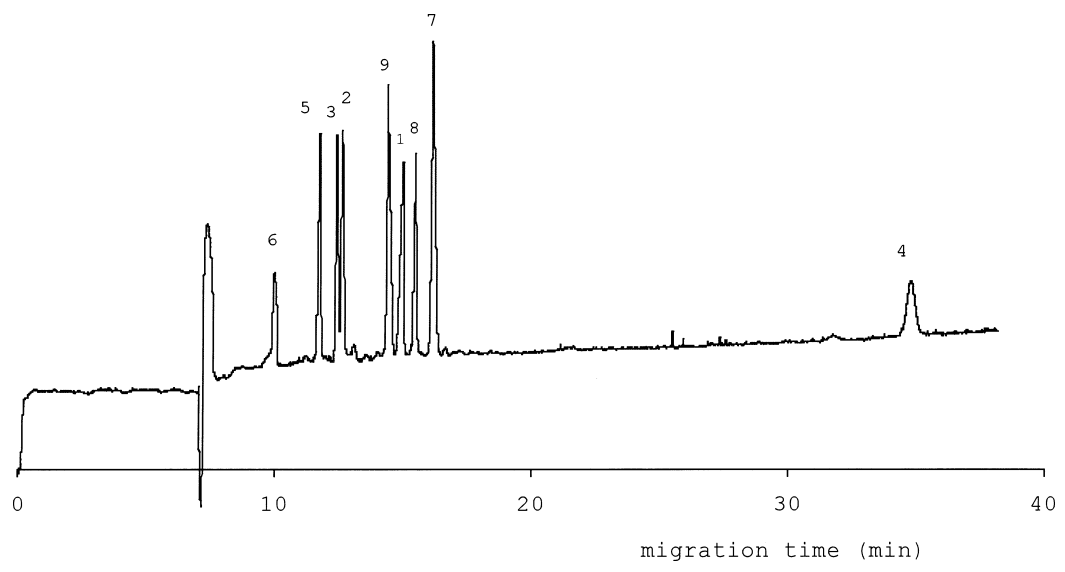

Fig. 2. CD-EKC Electropherogram Showing the Separation of Compounds 1-9

Using $0.03 \mathrm{~m}$ Borate buffer ( $\mathrm{pH} 10.0$ ) containing $0.005 \mathrm{~m} \alpha-\mathrm{CD}$ and $20 \% \mathrm{CH}_{3} \mathrm{CN}$.

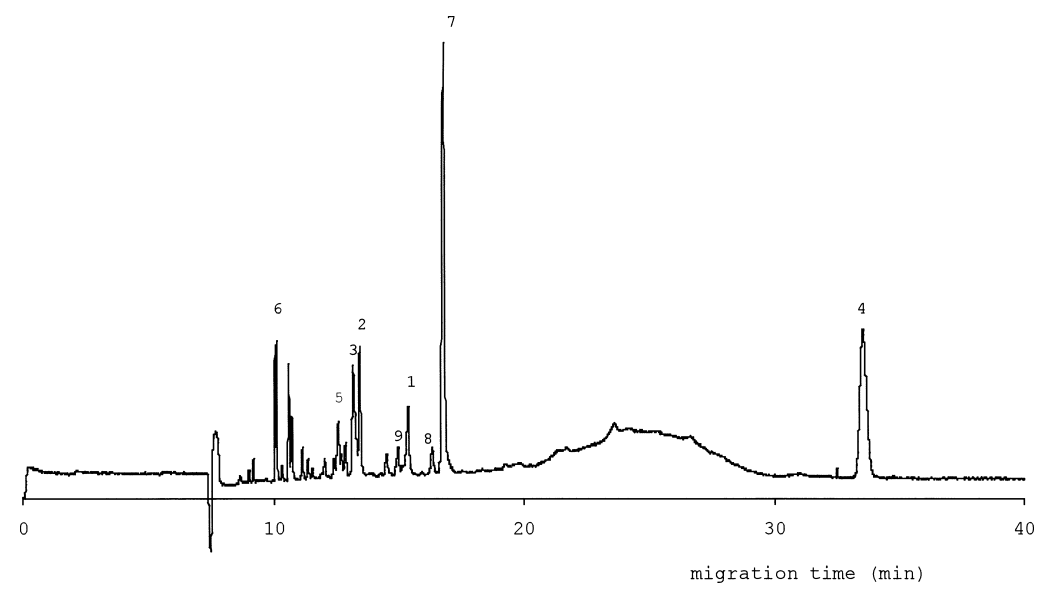

Fig. 3. CD-EKC Electropherogram Showing the Separation for the Extract of Rhei Rhizoma

Using $0.03 \mathrm{M}$ Borate buffer (pH 10.0) containing $0.005 \mathrm{~m} \alpha-\mathrm{CD}$ and $20 \% \mathrm{CH}_{3} \mathrm{CN}$.

als. It is well known that when the buffer concentration increases, the electro-osmotic flow decreases, and therefore the migration times increase. The $\mathrm{pH}$ dependence of the migration time of emodin was examined with $0.03 \mathrm{M}$ borate buffer in the $\mathrm{pH}$ range $8-11$. The migration time became longer as the $\mathrm{pH}$ value increased. We tried to separate the mixture of all compounds by CZE, micellar electrokinetic chromatography (MEKC) with SDS, CD-MEKC, and CD-CZE, changing the buffer solutions to different $\mathrm{pHs,} \mathrm{composition,} \mathrm{buffer}$ concentration, organic solvent, and other modifiers. It was found that a standard mixture could be resolved by CZE, CD-MEKC, and CD-CZE. Among them, only CD-CZE provided suitable performance for the qualitative and quantitative determination of anthraquinones, due to a little interference by the co-existence of the herbal extract. After examining a series of buffer solutions differing in $\mathrm{pH}(\mathrm{pH} 8-11)$, concentration $(0.005-0.1 \mathrm{M})$, and the nature $(\alpha, \beta, \gamma, \mathrm{HP}-\beta$ $\mathrm{CD}, \mathrm{HP}-\gamma-\mathrm{CD})$ and concentration of CDs $(0.005-0.03 \mathrm{M})$, it was found that a $0.03 \mathrm{~m}$ borate buffer $(\mathrm{pH} 10.0)$ containing 0.005 м $\alpha$-CD and $20 \%$ acetonitrile could simultaneously resolve emodin (1), chrysophanol (2), aloe-emodin (3), rhein (4), emodin-8- $\beta$-D-glucoside (5), chrysophanol-8- $\beta$-D-glucoside (6), rhein-8- $\beta$-D-glucoside (7), sennoside A (8), and sennoside $\mathrm{B}(\mathbf{9})$ in the extracts.

In $\mathrm{CZE}$, the main factor affecting the migration velocity of a sample molecule is generally determined by the molecular size/charge ratio. CDs have been successfully applied for the separation of several hydrophobic compounds. The shape of the $\mathrm{CD}$ is similar to that of a truncated cone with a relatively hydrophobic cavity which is able to host analytes, and a hydrophilic outside region due to the presence of hydroxyl groups. In the inclusion-complexation mechanism, the entire molecule fits into the CD cavity or with its hydrophobic part. In this work, the $\alpha$-CD may have an important role for separating the herbal extracts from a large number of co-existent interferences. The migration time of glucoside became longer as the concentration of the buffer and $\mathrm{pH}$ increased. This could be explained by the formation of an anionic borate complex with the ortho-dihydroxy group of the glucopyranosyl unit ${ }^{21)}$ and alkaline conditions are required to induce hydroxyl group ionization. Figure 2 is an electropherogram showing the separation of the nine authentic substances, and Fig. 3. is an electropherogram of the methanol extract of Rhei Rhizoma. (Similarity Index with UV; 1: 0.996, 2: 0.993, 3: $0.993,4: 0.997$, 5: $0.996,6: 0.999,7: 0.998$, 8: 0.998, 9: 0.993).

For the quantitative analysis, correlations between the peak area and the sample concentrations $(\mathbf{1}-\mathbf{3}, \mathbf{5}-\mathbf{9})$ were studied. The curves (peak-area ratios, $Y$, vs. concentration, $x$, $\mu \mathrm{g} / \mathrm{ml}$ ) were constructed in the range of $5-100 \mu \mathrm{g} / \mathrm{ml}$ for all 
Table 1. Concentration of Compounds $\mathbf{1}-\mathbf{3}, \mathbf{5}-\mathbf{9}$

\begin{tabular}{|c|c|c|c|c|c|c|c|c|}
\hline & $\begin{array}{c}\mathbf{1} \\
(\mathrm{mg} / \mathrm{g})\end{array}$ & $\begin{array}{c}\mathbf{2} \\
(\mathrm{mg} / \mathrm{g})\end{array}$ & $\begin{array}{c}\mathbf{3} \\
(\mathrm{mg} / \mathrm{g})\end{array}$ & $\begin{array}{c}\mathbf{5} \\
(\mathrm{mg} / \mathrm{g})\end{array}$ & $\begin{array}{c}\mathbf{6} \\
(\mathrm{mg} / \mathrm{g})\end{array}$ & $\begin{array}{c}7 \\
(\mathrm{mg} / \mathrm{g})\end{array}$ & $\begin{array}{c}\mathbf{8} \\
(\mathrm{mg} / \mathrm{g})\end{array}$ & $\begin{array}{c}9 \\
(\mathrm{mg} / \mathrm{g})\end{array}$ \\
\hline Rhei Rhizoma & 1.11 & 4.84 & 0.30 & 15.78 & 9.48 & 33.47 & 1.44 & 0.64 \\
\hline
\end{tabular}

Table 2. Reproducibility of Migration Times and Areas of Compounds $1-9$

\begin{tabular}{cccc}
\hline \hline Compound & $\begin{array}{c}\text { Migration time } \\
(\mathrm{min})\end{array}$ & $\begin{array}{c}\text { RSD of Migration time } \\
(\%)(n=5)\end{array}$ & $\begin{array}{c}\text { RSD of areas } \\
(\%)(n=3)\end{array}$ \\
\hline $\mathbf{1}$ & 15.04 & 1.80 & 1.64 \\
$\mathbf{2}$ & 12.66 & 1.59 & 1.63 \\
$\mathbf{3}$ & 12.45 & 1.47 & 2.49 \\
$\mathbf{4}$ & 34.75 & 3.58 & 3.67 \\
$\mathbf{5}$ & 11.82 & 1.73 & 1.36 \\
$\mathbf{6}$ & 10.04 & 1.40 & 3.00 \\
$\mathbf{7}$ & 16.21 & 1.83 & 2.86 \\
$\mathbf{8}$ & 15.49 & 1.82 & 2.36 \\
$\mathbf{9}$ & 14.49 & 1.84 & 0.34 \\
\hline
\end{tabular}

compounds. The regression equations of these curves and their correlation coefficients were calculated as follows: 1, $Y=3129 x-2238 \quad\left(r^{2}=0.995\right) ; \quad 2, \quad Y=1384 x+14802 \quad\left(r^{2}=\right.$ 1.000); 3, $Y=4392 x+9554\left(r^{2}=1.000\right) ; 5, \quad Y=176 x-447$ $\left(r^{2}=0.995\right) ; 6, Y=1139 x-11628\left(r^{2}=0.998\right) ; 7, Y=1144 x+$ $6089\left(r^{2}=0.998\right) ; 8, Y=5735 x-18493\left(r^{2}=0.998\right) ; 9, Y=$ $2645 x+3116\left(r^{2}=0.998\right)$.

At a signal-to-noise ratio of 3 , the detection limits of the analytes were: $1,0.1 \mu \mathrm{g} / \mathrm{ml} ; 2,0.3 \mu \mathrm{g} / \mathrm{ml} ; 3,0.4 \mu \mathrm{g} / \mathrm{ml} ; 5$, $0.6 \mu \mathrm{g} / \mathrm{ml} ; \mathbf{6}, 0.3 \mu \mathrm{g} / \mathrm{ml} ; 7,0.8 \mu \mathrm{g} / \mathrm{ml} ; \mathbf{8}, 0.3 \mu \mathrm{g} / \mathrm{ml} ; \mathbf{9}, 0.8 \mu \mathrm{g} /$ $\mathrm{ml}$.

The extraction recovery was tested by adding known amounts of $\mathbf{1}$ and $\mathbf{2}$. The ranges for the recovery of emodin were $103.5-108.2 \%$ and $97.6-104.6 \%$ for crysophanol $(n=5)$. The amounts of the compounds, except for 4 , found in these sample extracts are shown in Table 1.

The reproducibilities, expressed as the relative standard deviation (RSD) of this method calculated on the basis of the migration time and peak area over five and three replicate injections, are shown in Table 2 . The reproducibility of the migration time for an individual compound was between 1.40 and $3.58 \%$ RSD.

In conclusion, the simultaneous CD-CZE method described here has been successfully applied to the determina- tion of nine components in the untreated extract of Rhei Rhizoma, and is expected to be a useful technique for simultaneous determination of components that consist of anthraquinones and their glucosides showing a large difference in polarity.

\section{References}

1) Zhou J., Fang Z. Z., Li C. F., Zhao G., Chinese Traditional Patent Medicine, 10, 31 (1987).

2) Zong Y. Y., Che C. T., J. Nat. Products, 58, 577-582 (1995).

3) Birks J. W., Frei R. W., Trend Anal. Chem., 1, 361-367 (1982).

4) Takahashi K., Kaizuka H., Ohshima Y., J. Chromatogr., 268, 522-527 (1983).

5) Sagara K., Oshima T., Yoshida T., J. Chromatogr., 403, 253-261 (1987).

6) Ohshima Y., Ohno Y., Kajiyama K., Takahashi K., J. Chromatogr., 360, 303-306 (1986).

7) Poulsen J. R., Birks J. W., Leiter J., Anal. Chem., 61, 2267-2276 (1989).

8) Kashiwada Y., Nonaka G. I., Nishioka I., Chem. Pharm. Bull., 37, 999-1004 (1989).

9) Sheu S. J., Chen H. R., Anal. Chim. Acta, 309, 361-367 (1995).

10) Sheu S. J., Chen H. R., J. Chromatogr. A, 704, 141-148 (1995).

11) Weng W. C., Sheu S. J., J. High Resol. Chromatogr., 23, 143-148 (2000).

12) Koyama J., Toyokuni I., Tagahara K., Phytochem. Anal., 8, 135-138 (1997).

13) Koyama J., Morita I., Tagahara K., Bakari J., Aqil M., Chem. Pharm. Bull., 50, 1103-1105 (2002).

14) Koyama J., Morita I., Kawanishi K., Tagahara K., Kobayashi N., Chem. Pharm. Bull., 51, 418- 420 (2003).

15) Koyama J., Morita I., Tagahara K., Aqil M., Phytochemistry, 56, 849851 (1997).

16) Murakami T., Ikeda K., Takido M., Chem. Pharm. Bull., 16, 22992300 (1968).

17) Tsukida K., Yoneshige M., Yakugaku Zasshi, 74, 379-382 (1954).

18) Horhammer L., Bittner G., Horhammer H. P., Naturwissenschften, 51, 310-311 (1964).

19) Bellaart A. C., Chem. Ber., 99, 2471-2472 (1966)

20) Oshio H., Naruse Y., Tsukui M., Chem. Pharm. Bull., 26, 2458-2464 (1978).

21) Morin Ph., Villard F., Dreux M., J. Chromatogr., 628, 161-169 (1993). 